\title{
Is there any advantage of using stand-alone cages? A numerical approach
}

\author{
Andrea Calvo-Echenique, José Cegoñino and Amaya Perez del Palomar ${ }^{*}$ (1)
}

*Correspondence:
amaya@unizar.es
Group of Biomaterials,
Aragón Institute
of Engineering Research
(I3A), Mechanical Engineering
Department, University
of Zaragoza, C/Maria de Luna
s/n. Betancourt Building,
50018 Saragossa, Spain

Methods: A non-linear FE model of the whole lumbar spine was developed to comment of the adjacent segments to the operated one was studied. Moreover, the risk of subsidence of the cages was qualitatively evaluated.

its: A great ROM reduction occurred when supplementary fixation was used. the overloading of these segments could be related with the clinically observed adjacent disc degeneration. Meanwhile, the stand-alone cages allowed for a wider movement, and therefore, the influence of the surgery on adjacent discs was much lower. Regarding the risk of subsidence, the contact pressure magnitude was similar for both intervertebral cage designs and near the value of the maximum tolerable pressure of

Conclusions: A minimally invasive posterior insertion of an intervertebral cage (OLYS or NEOLIF) was compared using a stand-alone design or adding supplementary fixation. The outcomes of these two techniques were compared, and although standalone cage may diminish the risk of disease progression to the adjacent discs, the spinal movement in this case could compromise the vertebral fusion and might present a higher risk of cage subsidence.

Keywords: Finite element method, Intervertebral disc, Lumbar spine, Stand-alone cages, Posterior screw fixation, Posterior lumbar interbody fusion

\section{Introduction}

Segment fusion with intradiscal cage and pedicle screw fixation (PSF) is the "gold standard" treatment for lumbar hernia and degenerative intervertebral disc (IVD) diseases. However, stand-alone interbody cages have shown to be a feasible surgical technique for the treatment of discogenic back pain [1,2]. A simple discectomy without cage insertion reduces the disc height creating slack in all longitudinal ligaments [3]. Nevertheless, 
if the IVD space is distracted by a cage insertion, the ligaments are pre-strained contributing to spine stabilisation [4]. Furthermore, using a minimally invasive approach, important stabilising structures such as posterior musculature, anterior and posterior longitudinal ligaments, and facet joints are preserved helping to control segment kinematics [5-7]. In spite of that, some physicians advocate for the use of supplementary PSF to assure long-term stabilisation and segment fusion [8, 9]. Few clinical prospective randomised studies have been comparing stand-alone construct versus fusion with supplemental PSF $[10,11]$. These studies did not show significant differences in clinical outcomes whilst several advantages were reported for the use of stand-alone cages in degenerated lumbar segments without previous instability: the surgical technique is less demanding, it takes less time, the implant cost is lower and pedicle screw-related complications are avoided. Besides, different cohorts of patients undergoing a stand-alone cage implantation have been followed up showing good clinical outcomes, a high rate of fusion and a low incidence of both cage subsidence and cage migration [1, 2, 12-15]. Finally, comparisons of cages with and without different supplemental fixations have been performed in vitro in human lumbar spines [16-18].

Several computational works have been developed using finite element (FE) models to simulate lumbar biomechanics after cage insertion in single functional spinal unit (FSU) [19-21] or complete lumbar spine [22-25]. All of them studied the spinal movement showing that PSF provided a higher segment stiffness than stand-alone cages [26, 27], but segment stability was also reported for the last ones. Since the goal of lumbar surgery is not only to stabilise the segment but also to restore the IVD space and maintain the lumbar lordosis, the major concerns regarding surgery complications are segmental instability [28], cage subsidence [4] and cage migration [29]. Furthermore, lumbar fusion has been associated with the risk of adjacent segment disease because it alters the biomechanical environment of the whole spine [30]. However, as far as the authors' knowledge, all these key factors have not been studied together in a complete lumbar spine model using complex constitutive models for the biological tissues involved.

On the other hand, ligaments play an important role in segment behaviour, particularly in bending. Ligament pre-strain is thought to be responsible for spinal stability in the absence of active muscle contraction [31]. However, ligament pretension is often overlooked or not reported in lumbar spine FE models because of the lack of experimental values. Recently, some FE studies have introduced the experimentally characterised pre-strain of some spinal ligaments in healthy lumbar spines [32,33] showing their influence on the overall spine biomechanics. Despite the importance that the ligament prestrain may have on lumbar surgery success, few computational works have considered this condition after cage insertion [19].

In this work, an FE model of the whole human lumbar healthy spine was developed, and then this model was modified to insert an intervertebral cage in L4-L5 segment in a stand-alone fashion or in combination with PSF. In addition, two different cage designs were compared. In addition, the role that ligament pre-stresses play in spinal behaviour was discussed in a functional spinal unit (FSU). Thus, the goal of this study was to analyse the influence that each surgery has over the biomechanics of the affected and adjacent segments and discuss the outcomes of each of them. 


\section{Materials and methods}

In this paper, the insertion of two different types of intervertebral cages at L4-L5 level with and without posterior screw fixation (PSF) is analysed. For both the scenarios (with or without PSF), a minimally invasive surgery is simulated. This means that only a discectomy is performed and an intervertebral cage is inserted, not removing any additional tissue [34].

A porohyperelastic FE model of the whole lumbar spine (L1-S1) from previous works was used as the intact model [35]. This model was modified to construct four different FE models adding instrumentation as shown in Fig. 1. These models can be summarised as follows: (1) Intact; (2) Stand-alone cage (OLYS); (3) Stand-alone cage (NEOLIF); (4) Cage (OLYS) + PSF; and (5) Cage (NEOLIF) + PSF. All of them

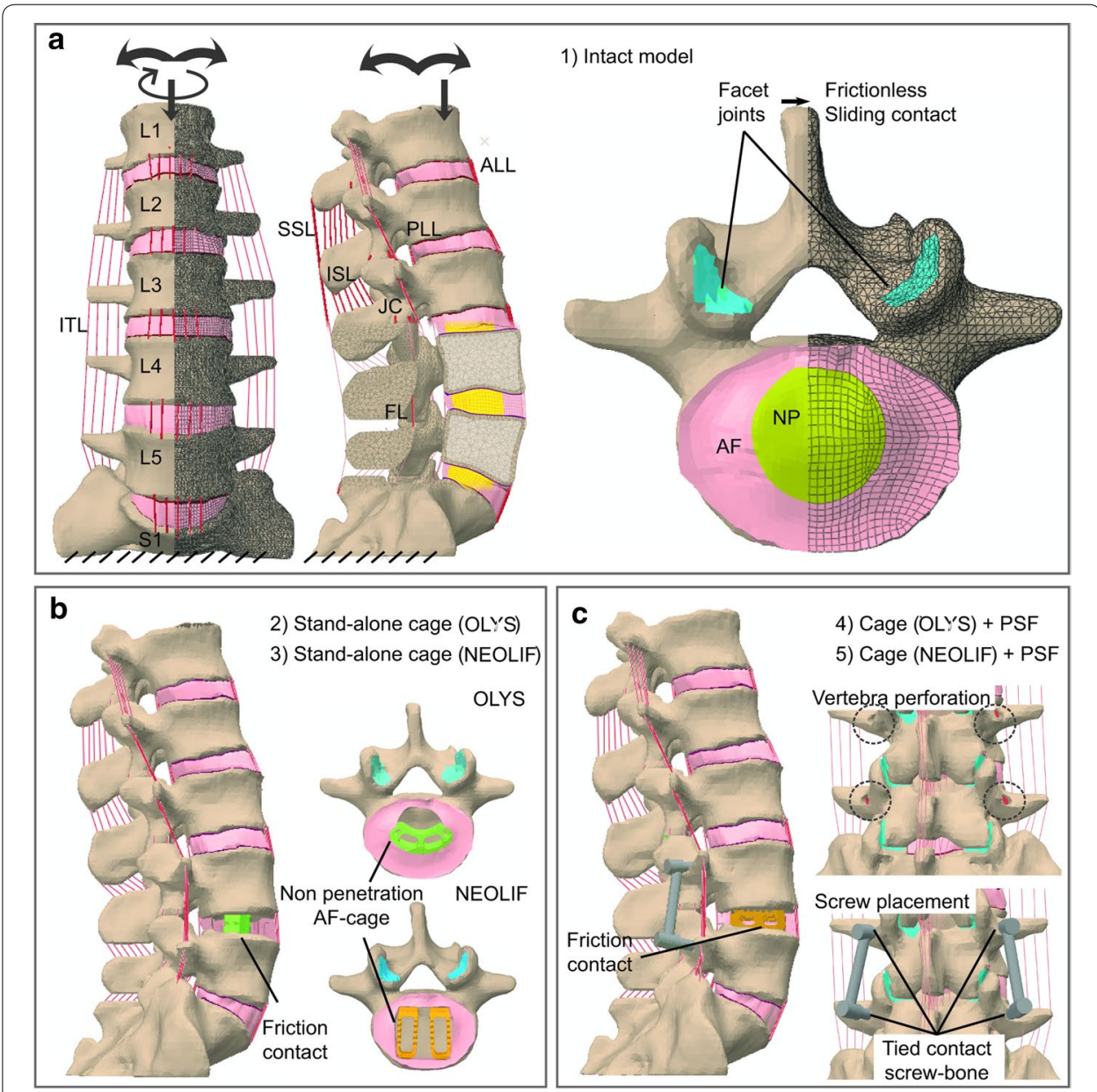

Fig. 1 FE model of the lumbar spine. a (1) Intact model (L1-S1). Frontal and lateral view of the whole lumbar spine with a schematic representation of the boundary and loading conditions and the ligaments [antero-longitudinal ligament (ALL); postero-longitudinal ligament (PLL); intertransverse ligament (ITL); interspinous ligament (ISL); capsular ligaments (JC); flaval ligament (FL); supraspinous ligament (SSL)] (left). Top view of $\mathrm{L} 5$ and the disc between $\mathrm{L} 4-\mathrm{L} 5$ (right). $\mathbf{b}$ Stand-alone models. Two different cages were introduced in the L4-L5 interbody space: (2) OLYS cage and (3) NEOLIF cage. A lateral view of the whole lumbar spine and the top view of cages placement are shown. c Cage + PSF models. The stand-alone models have been supplemented with PSF after the perforation of L4 and L5 vertebrae: (4) OLYS + PSF and (5) NEOLIF + PSF 
were subjected to the same boundary and loading conditions. A total displacement and rotation restriction was imposed on the lower face of the sacrum. Eight hours of free swelling in which the internal fixed charge concentration is equilibrated with the external solution by means of the osmotic pressure was simulated [36]. A preload of $100 \mathrm{~N}$ was applied at the centroid of vertebra $\mathrm{L} 1$ followed by $\pm 10 \mathrm{Nm}$ moment load in flexion-extension, lateral bending (LB) or axial rotation (AR) [18, 37, 38]. All simulations were performed using ABAQUS 6.13 (SIMULIA, Providence, RI, USA).

\section{Intact model}

Intact model is briefly described; more details can be found elsewhere [35, 39]. A computed tomography $(\mathrm{CT})$ of the lumbar spine from a healthy patient was used to reconstruct the bone geometry (slices obtained by $0.5 \mathrm{~mm}$ intervals of $512 \times 512$ resolution). After segmentation, soft tissues were modelled according to the anatomical characteristics as shown in Fig. 1a. Vertebral bodies were meshed using linear tetrahedral elements of $2 \mathrm{~mm}$ size, and linear poroelastic properties were assigned differentiating between cortical and trabecular bones. The IVDs consisted of annulus fibrosus (AF), nucleus pulposus (NP) and endplates (EP). These were meshed with linear hexahedral elements after a sensibility test to determine a mesh size of $1.5 \mathrm{~mm}$. The EPs were characterised as poroelastic materials, the AF was characterised as anisotropic porohyperelastic material with two families of fibres, using the Holzapfel strain energy function, and the NP as anisotropic porohyperelastic neo-Hookean material. The osmotic behaviour was included in both AF and NP. The constitutive model of the IVD, as well as the annulus fibres orientation $\left( \pm 30^{\circ}\right)$, was implemented in an UMAT user subroutine [35]. The seven spinal ligaments (see Fig. 1a) were modelled as uniaxial truss elements with straindependent behaviour under traction and without resistance to compression. Initial ligament pre-strain was set as the initial condition according to the experimental values from literature [32]: 5.3\% for anterior longitudinal ligament (ALL) and 4.3\% for interspinous ligament (ISL). The facet joints were modelled as frictionless surface-to-surface contact combined with a penalty algorithm for normal contact, with a normal contact stiffness of $200 \mathrm{~N} / \mathrm{m}$ (see Fig. 1a, right). A $0.2 \mathrm{~mm}$ thickness was assigned to the cartilage of the facet joints, which was assumed to be linearly elastic and isotropic [40]. All material properties are summed up in Table 1.

\section{Stand-alone cage surgery}

Two different commercial cages were modelled using Rhinoceros 5.0 (Robert McNeil \& Associates, USA): the first one, commonly used for TLIF (transforaminal lumbar interbody fusion) approach was a single bean-shaped piece (OLYS ${ }^{\circledR}$, Scient'x, Alphatec Spine Inc., France) [50]; the second, normally used for PLIF (posterior lumbar interbody fusion) approach, consisted of two rectangular parallel pieces (NEOLIF ${ }^{\circledR}$, Biomet, Germany) [51]. The geometry of both was extracted from the commercial catalogues provided by the companies which include the most relevant dimensions. Both of them were made of PEEK ( $E=3600 \mathrm{MPa}, v=0.38)$ [50] and were meshed with tetrahedral elements with a mean element size of $0.5 \mathrm{~mm}$. As a minimally invasive technique was simulated, only the nucleus pulposus was removed from the disc and the rest of the structures (annulus fibrosus, endplates, facet joints and ligaments) remained intact [51]. The cages 
Table 1 Elastic [ $E$ and $v$ for elastic material; $C_{10}, C_{20}, D, K_{1}$ and $K_{2}$ for a hyperelastic model (Holzapfel strain energy function); $E_{1}, E_{2}$ and $\varepsilon_{12}$ for bilinear elastic model] and biphasic material properties $\left(k_{0}\right.$ : initial permeability, $e$ : void ratio, $c_{F, 0}$ : initial fixed charged density, $n_{\mathrm{F}, 0}$ : initial porosity) assigned to the different tissues to simulate the spine behaviour in healthy and degenerated (degenerated annulus-Grade IV) state

\begin{tabular}{|c|c|c|c|c|c|c|c|c|c|}
\hline & \multicolumn{2}{|c|}{ Elastic parameters } & \multicolumn{7}{|c|}{ Biphasic parameters } \\
\hline & $E(\mathrm{MPa})$ & $v$ & $k_{0}\left(\mathrm{~m}^{4} / \mathrm{Ns}\right)$ & $e$ & $\begin{array}{l}c_{\mathrm{F}, 0}(\text { meq } / \\
\left.\mathrm{mm}^{3}\right)\end{array}$ & \multicolumn{4}{|l|}{$n_{\mathrm{F}, 0}$} \\
\hline $\begin{array}{l}\text { Cortical } \\
\text { bone [41, } \\
42]\end{array}$ & 17,000 & 0.3 & $5.77 \times 10^{-18}$ & 0.05 & - & 0.05 & & & \\
\hline $\begin{array}{l}\text { Cancellous } \\
\text { bone [41, } \\
42]\end{array}$ & 100 & 0.2 & $5.55 \times 10^{-11}$ & 0.41 & - & 0.29 & & & \\
\hline $\begin{array}{l}\text { Endplate } \\
\quad[41,42]\end{array}$ & 20 & 0.4 & $7.22 \times 10^{-13}$ & 4 & - & 0.8 & & & \\
\hline $\begin{array}{l}\text { Cartilage } \\
{[40]}\end{array}$ & 35 & 0.4 & & & & & & & \\
\hline \multirow{3}{*}{$\begin{array}{c}\text { Granular } \\
\text { tissue } \\
{[43]}\end{array}$} & 0.2 & 0.167 & & & & & & & \\
\hline & \multicolumn{5}{|c|}{ Elastic parameters } & \multicolumn{4}{|c|}{ Biphasic parameters } \\
\hline & $C_{10}(\mathrm{MPa})$ & $C_{20}(\mathrm{MPa})$ & $D\left(\mathrm{MPa}^{-1}\right)$ & $K_{1}(\mathrm{MPa})$ & $K_{2}$ & $k_{0}\left(\mathrm{~m}^{4} / \mathrm{Ns}\right)$ & $e$ & $\begin{array}{l}c_{\mathrm{F}, 0}(\mathrm{meq} / \\
\left.\mathrm{mm}^{3}\right)\end{array}$ & $n_{\mathrm{F}, 0}$ \\
\hline $\begin{array}{c}\text { Annulus } \\
{[39,44} \\
45]\end{array}$ & 0.1 & 2.5 & 0.306 & 1.8 & 11 & $1.85 \times 10^{-15}$ & 2.7 & $1.8 \times 10^{-4}$ & 0.72 \\
\hline $\begin{array}{l}\text { Degener- } \\
\text { ated } \\
\text { annulus } \\
{[46,47]}\end{array}$ & 0.45 & 2.5 & 0.306 & 1.8 & 11 & $1.45 \times 10^{-15}$ & 2.4 & $0.9 \times 10^{-4}$ & 0.7 \\
\hline $\begin{array}{c}\text { Nucleus } \\
{[39,44,} \\
45]\end{array}$ & 0.16 & 0 & 0.024 & - & - & $1.92 \times 10^{-16}$ & 4.8 & $2.4 \times 10^{-4}$ & 0.8 \\
\hline \multirow{2}{*}{$\begin{array}{l}\text { Ligaments } \\
{[32,48,49]}\end{array}$} & \multicolumn{3}{|c|}{ Elastic parameters } & \multicolumn{6}{|c|}{ Biphasic parameters } \\
\hline & $E_{1}(\mathrm{MPa})$ & $E_{2}(\mathrm{MPa})$ & $\varepsilon_{12}$ & $\begin{array}{l}\text { Number } \\
\text { of elements }\end{array}$ & $\begin{array}{l}\text { Area } \\
\left(\mathrm{mm}^{2}\right)\end{array}$ & $\begin{array}{l}\text { Pre-stress } \\
\text { (MPa) }\end{array}$ & & & \\
\hline ALL & 7.8 & 20.0 & 0.12 & 10 & 32.9 & 0.804 & & & \\
\hline PLL & 1.0 & 2.0 & 0.11 & 9 & 5.2 & 0.019 & & & \\
\hline LF & 1.5 & 1.9 & 0.062 & 6 & 84.2 & 0.02 & & & \\
\hline ITL & 10.0 & 59.0 & 0.18 & 16 & 1.8 & 0.026 & & & \\
\hline \multirow[t]{3}{*}{ SSL } & 3.0 & 5.0 & 0.2 & 4 & 25.2 & 0.017 & & & \\
\hline & \multicolumn{3}{|c|}{ Elastic parameters } & \multicolumn{6}{|c|}{ Biphasic parameters } \\
\hline & $\begin{array}{l}\text { Spine } \\
\text { level }\end{array}$ & $\begin{array}{l}\text { Stiffness } \\
(\mathrm{N} / \mathrm{mm})\end{array}$ & $v$ & $\begin{array}{l}\text { Number } \\
\text { of elements }\end{array}$ & $\begin{array}{ll} & \text { Area } \\
& \left(\mathrm{mm}^{2}\right)\end{array}$ & $\begin{array}{l}\text { Pre-stress } \\
\text { (MPa) }\end{array}$ & & & \\
\hline \multirow[t]{5}{*}{$J C$} & $\mathrm{~L} 1-\mathrm{L} 2$ & $42.5 \pm 0.8$ & 0.4 & 14 & 43.8 & 0.237 & & & \\
\hline & $\mathrm{L} 2-\mathrm{L} 3$ & $33.9 \pm 19.2$ & & & & & & & \\
\hline & L3-L4 & $32.3 \pm 3.3$ & & & & & & & \\
\hline & L4-L5 & $30.6 \pm 1.5$ & & & & & & & \\
\hline & L5--S1 & $29.9 \pm 22.0$ & & & & & & & \\
\hline \multirow[t]{5}{*}{ ISL } & $\mathrm{L} 1-\mathrm{L} 2$ & $10.0 \pm 5.2$ & 0.4 & 11 & 35.1 & 0.028 & & & \\
\hline & L2-L3 & $9.6 \pm 4.8$ & & & & & & & \\
\hline & L3-L4 & $18.1 \pm 15.9$ & & & & & & & \\
\hline & L4-L5 & $8.7 \pm 6.5$ & & & & & & & \\
\hline & L5-S1 & $16.3 \pm 15.0$ & & & & & & & \\
\hline
\end{tabular}




\section{Table 1 (continued)}

The pre-stress (equivalent to $5 \%$ of space distraction) applied to L4-L5 segment ligaments, in case of stand-alone surgery, is also reported in the last column. The following notation is used for ligaments: ALL-antero-longitudinal ligament; PLLpostero-longitudinal ligament; LF-ligamentum flavum; ITL-intertransverse ligament; SSL—supraspinous ligament; JCcapsular ligament; ISL-interspinous ligament

were placed as shown in Fig. 1b. After the insertion, the empty region left between the annulus and the cage was filled with tetrahedral elements simulating granulation or inflammatory tissue (its mechanical properties are shown in Table 1) [43]. The penetration of the cage into the granulation tissue was avoided with a normal non-penetrating contact as well as the penetration of the cage through the annulus. Surface-to-surface sliding contact with high friction coefficient (0.8) [52] was set in the cage-endplate interface considering the effect of the serrated faces of the cages. The implant size was determined according to the patient spine geometry: $12 \mathrm{~mm}$ height for OLYS cage and $10 \mathrm{~mm}$ height for NEOLIF. The remaining AF was characterised as Grade IV degenerated tissue based on the Thompson grading system [53] with the material properties outlined in Table 1. A 5\% of intervertebral space distraction was considered [19] and the corresponding ligament pre-stress was introduced in the model as the initial condition (Table I).

In addition, when an intervertebral cage is inserted some intervertebral distraction is exerted to improve the stability of the operated segment [54]. Therefore, here, the sensibility of the lumbar segment motion to ligament pre-stress was studied in an FSU (L4-L5 segment) instrumented with a stand-alone OLYS cage for the same loading conditions. In this case, the bottom surface of L5 was fixed. The FSU motion was tested in all loading directions for distractions ranging from 0 to $20 \%$ of the intact disc height, taking into account that each distraction caused a different initial pre-stress of the ligaments. Figure 2 shows the pre-stress value for each ligament depending on the intervertebral space distraction. It can be seen that the highest pre-stress appeared in ALL. Moreover, the non-linear behaviour of the ligaments can be appreciated in the bottom part of the figure.

\section{Cage insertion with posterior screw fixation}

To provide additional stability, the previous models were supplemented with PSF. L4 and L5 vertebrae were perforated before screw insertion as shown in Fig. 1c. A tie contact was assumed at the bone-screw interface. The fixation (diameter of rods and screws of $5 \mathrm{~mm}$ ) was made of titanium ( $E=100000 \mathrm{MPa}, v=0.33)$ [55] and meshed with tetrahedral elements of $1 \mathrm{~mm}$ size.

\section{Results}

Validation

The intact model was validated comparing the ROM of each segment with experimental and computational results from the literature [37, 56-58] as shown in Additional file 1. Two different validations were made. First, each segment range of motion was compared to experimental data and computational results found in the literature. This comparison was made for the principal rotations axes (flexion-extension, lateral bending and axial 

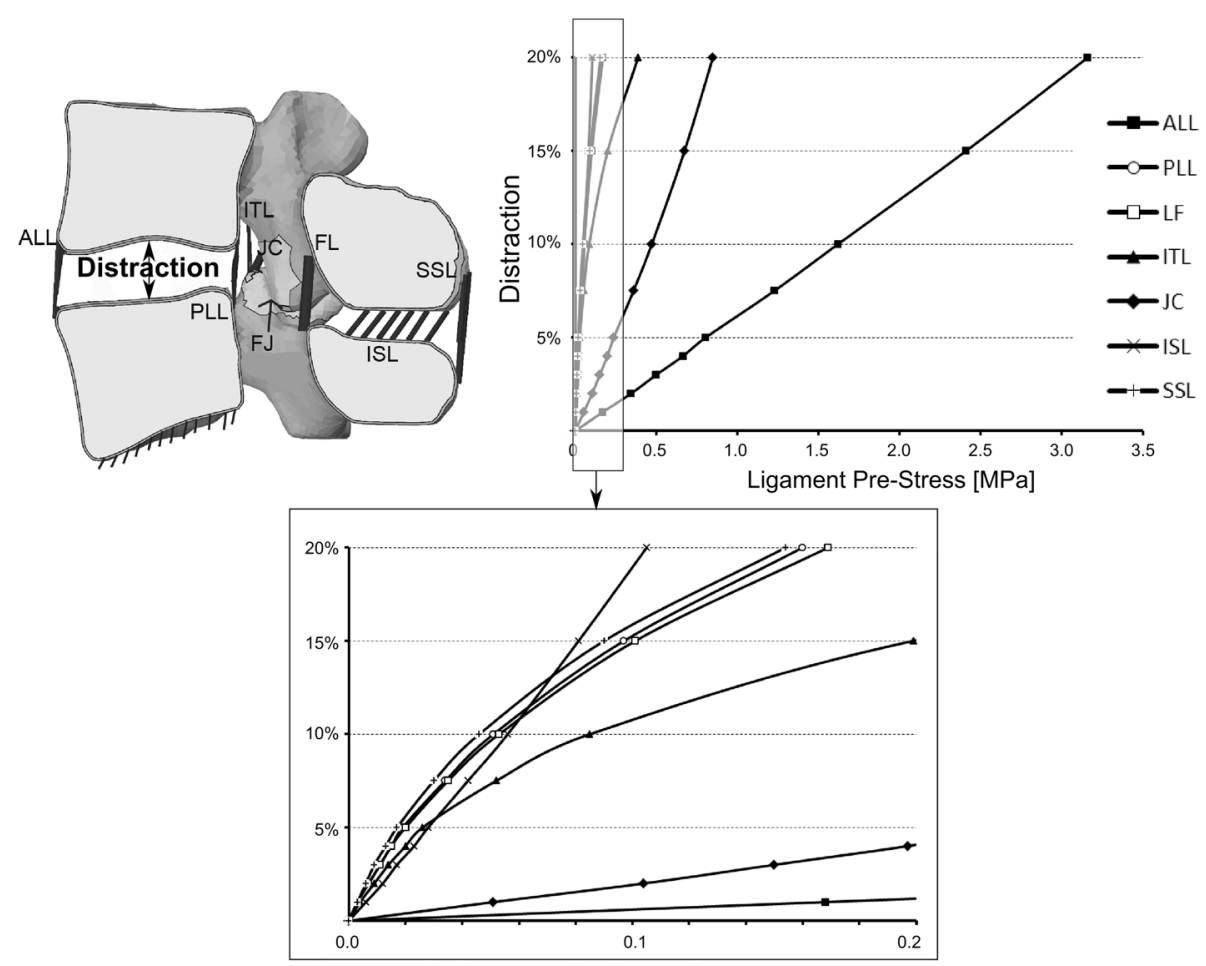

Fig. 2 Ligament pre-stress in stand-alone model caused by intervertebral space distraction (from 0 to 20\% of the intact IVD height) during cage insertion

rotation). It was seen that both for flexion-extension movement and lateral bending the correspondence between our results and those of the literature was very high. This was not the case for axial rotation, where more significant differences were obtained.

Furthermore, an additional validation with different moment value was also performed. The more recent study of Campbell et al. [58] was used, and here the total rotation of the lumbar spine (L1-L5 rotation) was evaluated. In this case, the results for extension, lateral bending and axial rotation perfectly fitted within Campbell et al. results. However, the flexion rotation in our simulations was higher.

Therefore, the present finite element model can represent the non-linear behaviour of the human lumbar spine and can serve as a reference to qualitatively analyse the changes when some modification in the mechanical environment of the spine is simulated.

\section{Movement of the affected segment (L4-L5 segment)}

Moment-rotation curves were analysed and compared for the five finite element models to see the effect of each surgery over the segment mobility (Fig. 3). When PSF was used, a drastic loss of motion occurred regardless the load direction or the type of intervertebral cage. In these cases, the immobilisation was more pronounced in flexion, extension and LB than in AR. Meanwhile, the stand-alone cages allowed for a wider ROM without exceeding the movement of the intact segment. The stiffness, defined as the moment applied divided by the ROM achieved, of L4-L5 segment in models (2) and (3) was greater in extension and AR movements (around 75\%) than in flexion and LB (around 25\%). Comparing between cages, the OLYS (2) showed a higher ROM restriction for AR, 


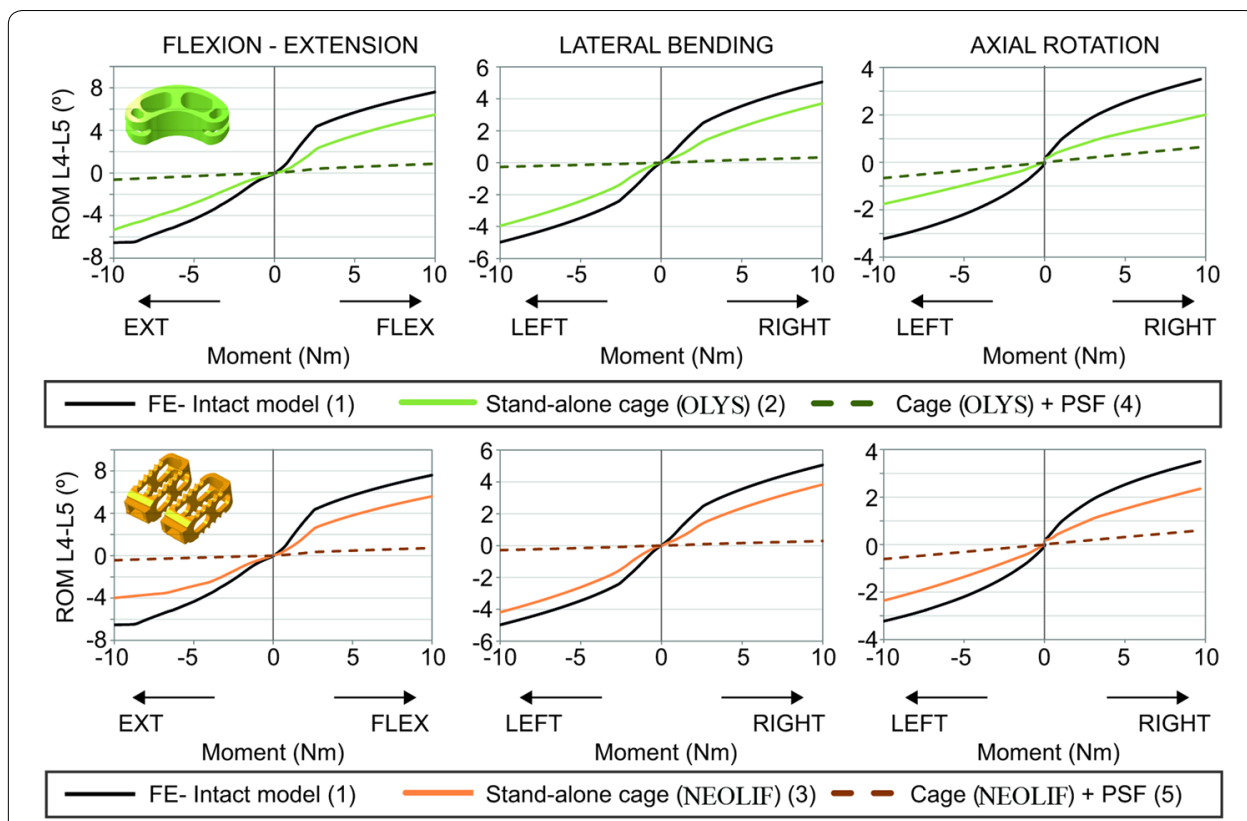

Fig. 3 Moment-rotation curves. Range of motion in L4-L5 segments in flexion, extension, lateral bending and axial rotation for OLYS (top) and NEOLIF (bottom) approaches in comparison with the intact movement

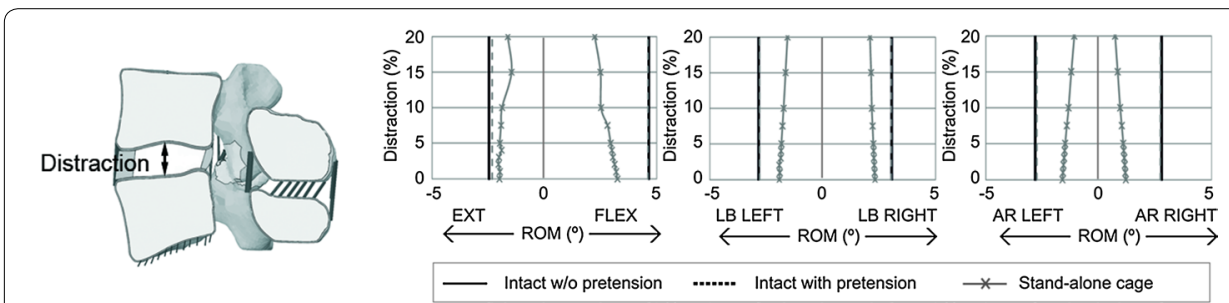

Fig. 4 FSU analysis of the influence of ligament pretension. Range of motion of an FSU in which the pretension of the ligaments due to intervertebral space distraction is considered. The value of the distraction is introduced as a percentage of the height of the intact intervertebral disc. The ROM for each moment is shown for an intact FSU with and without pretension, and for an operated segment with a stand-alone cage

whereas NEOLIF (3) reduced more the extension rotation. In flexion and LB, the behaviour of the spine with both implants was similar.

On the other hand, as it is common to introduce a cage a little wider than the intervertebral space [54], the influence of the ligament pre-stress was also studied. For that, only an FSU was analysed and different pretension of the ligaments was taken into account. As mentioned previously, Fig. 2 shows the initial stress of each ligament for different space distraction. It was obtained that ALL, JC and, at high distraction levels, ITL were mostly affected by space distraction. The influence of this ligament pretension can be seen in the movement of the FSU (Fig. 4). The segment rotation is shown for an intact FSU with and without considering the initial pretension and for an operated FSU with the initial pretension. The movement was reduced in all loading directions by increasing the distraction. ALL affected the extension movement, whilst JC decreased the rotation primarily in flexion and axial rotation. Lateral bending movements were the less 
influenced by the pre-stress. For instance, for $10 \%$ distraction, flexion and AR ROM decreased around $20 \%$.

\section{Subsidence risk}

The subsidence risk is related to the contact pressures that the cages exerted on the endplates. These pressures appear on the interfaces between cage and bone during loading. When this pressure exceeds the yield stress of the underlying material, a plastic deformation occurs and then the cage can penetrate inside the bone decreasing the intervertebral space height [59].

In our calculations, when PSF was introduced, the loads were distributed between the cages and the fixation and therefore the contact pressures were low. The behaviour was totally different for stand-alone cage models. Thus, the subsidence risk was only analysed in finite element models (2) and (3), and the contact pressures for the different movements were evaluated for OLYS and NEOLIF stand-alone cages. These results are shown in Fig. 5. It can be seen that the maximum value of the contact pressure (around $5 \mathrm{MPa}$ ) was similar for both the designs.

On the other hand, although there were no significant differences between OLYS and NEOLIF designs, the footprint left by each cage was different. Figure 5 shows the bottom endplate of L4 and the top surface of L5. The contact pressure distribution depends on the analysed movement. For instance for flexion movement, the pressures were distributed on the anterior part of the endplate, whilst for extension these were located on the posterior part. When NEOLIF was used, the pressure was more concentrated at the corners of the cages, whilst with the OLYS cage the contact pressures were distributed in a larger area on the central region. The pressures were in general smaller for the NEOLIF cage for every movement; this result was more obvious for axial rotation.

\section{Biomechanical changes in operated and adjacent levels}

Finally, in the remaining AF of the operated segment (L4-L5), the maximal and minimal principal stresses almost disappeared when PSF was used in flexion-extension and lateral bending, and they were reduced to a half in axial rotation, as shown in Fig. 6. On the other hand, when no PSF was added, the AF tissue of the operated segment absorbs a high percentage of the compressive loads and therefore the compressive stresses were higher than those of the intact discs whilst tension stresses were lower. This result can be extended to all loading cases with the only exception of NEOLIF cage in right rotation.

Attending to the adjacent segments, PSF caused a higher increase of principal stresses in both the segments as shown in Fig. 6. In flexion, the increase in stresses was more pronounced in the upper adjacent disc than in the lower one. However, in LB and AR, the influence over upper and lower discs was similar but depends on the load direction and the type of cage. When there was no posterior fixation, the stresses in the adjacent discs experienced a minor increase but it was also higher in the cranial disc than in the caudal disc for every movement. 


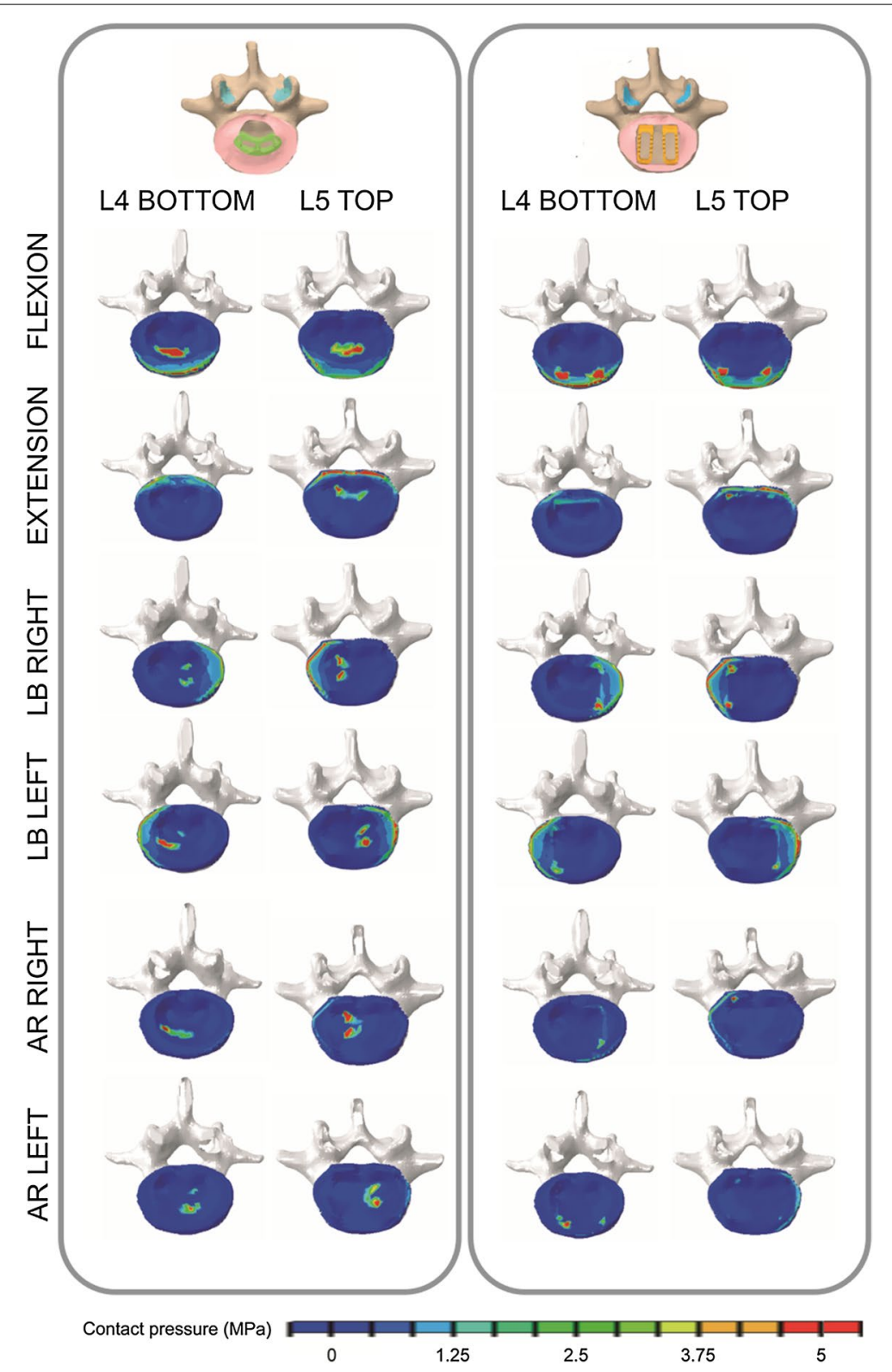

Fig. 5 Contact footprints. Contact pressure distribution on the top endplate of $L 5$ and bottom endplate of $L 4$ for both stand-alone cages in each rotation movement

\section{Discussion}

The main goal of this work was to compare between two different intervertebral lumbar cages with and without supplemental PSF and argue if stand-alone cage is a feasible solution for lumbar disc degeneration and hernia.

First, the intact finite element model was validated. In general, a good accordance was obtained between our results and those of the literature. For the case of axial rotation, the differences were higher. However, these disagreements were also obtained by the numerical simulations of Park et al. [57] and they can be related with the tissues involved in the cadaveric specimens of Panjabi et al. [37], which are not considered in the 


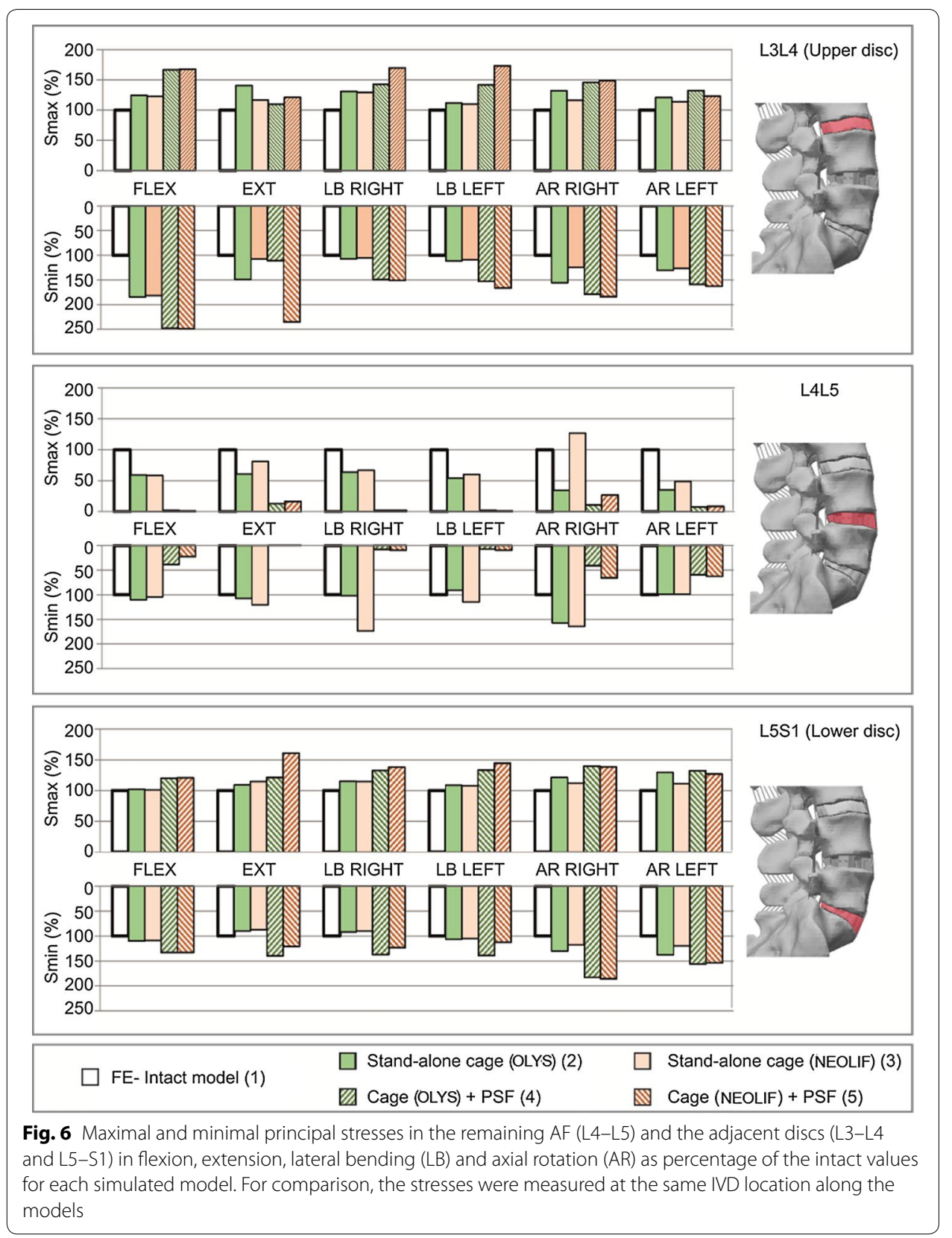

computational models. Moreover, the discrepancies for every movement were higher as the rotation was measured in the most caudal level of the spine. This can be explained by the fact that constraints were applied in S1. Another explanation could be related with the ligaments behaviour. We have to take into account that ligaments are rather different from upper to lower levels with different area and mechanical properties. However, due to the lack of data in the literature, we used the same definition at all levels, with exception of JC and ISL ligaments.

Attending to the operated spines [models (2) to (5)], the results revealed a drastic reduction in ROM when PSF was used whilst stand-alone cages allowed for a greater ROM. Considering that spine instability occurs if the ROM of the affected segment 
exceeds that of the intact segment for the same moment load [60], in our simulations, all the different models (with and without posterior fixation) showed that all the segments were stable since the stiffness increased in all cases. However, PSF achieved a much more stable union in all cases. The movement of the operated segment, although it remained stable, was high and therefore this type of surgery might compromise the complete fusion of the vertebra. Nevertheless, stand-alone cages have proven to be sufficient for intervertebral fusion when used in combination with bone graft [2, 13, 61]. Furthermore, when no graft is added, a fibrosis occurred around the implant preventing from migration and preserving some segmental motion [51].

Other authors have evaluated the ROM for a variety of cage designs and load magnitudes from the computational and experimental point of view. In vitro studies have reported ROM reductions with stand-alone cages between 6 and 70\% of the intact movement in flexion-extension and LB for complete lumbar spines [17,62] or FSUs [38]. This wide range in experimental findings may be caused by the different cages and surgical approaches used. However, all of them agreed with our results in showing that the restriction in the AR is lower and, in some cases, it was even higher than the intact movement. Moreover, all of them reported a significantly greater segmental stiffness when posterior screw fixation was added. As well as, in vitro studies, FE models from literature also reported a broad range of ROM reduction depending on the cage design and cage material in the whole lumbar spine $[22,63]$ and FSU $[19,21]$. However, as happened in experimental works all of them showed a less stabilisation for AR and stiffer segments with the use of PSF, which is in accordance with the results of this work except in AR with stand-alone cages. In this work, the segment was stiffer in AR, which could be a consequence of ligament pre-stress, especially of the capsular ligaments. Here, the role of ligament pre-stress, due to cage insertion, in the stabilisation of the segment was considered. ALL and JC ligaments, which are dominant under extension [64], were the most affected by space distraction. Consequently, the ROM in extension was reduced with increasing distraction. The capsular ligaments also restricted flexion and AR movements, providing additional stability.

Apart from stability, the interaction between cage and endplate was studied. Cage subsidence is one of the most common causes of failure in lumbar surgeries [13,29] and contact pressure can be related to this phenomenon [65]. The loss of disc height due to subsidence (i.e. the device sinking through the endplate) causes loss of correction in approximately $30 \%$ of the operated cases [59]. For PSF models, the contact pressures were very low and therefore it can be assumed that there would not be risk of subsidence. However, for the stand-alone constructs the behaviour was different, since the stiffest part of the model, which now corresponds to the stand-alone cage, absorbs most part of the loading. The pressure values was similar for both the designs (OLYS and NEOLIF), and this value should be compared with the yield stress of the endplates. Patel et al. [59] found that the maximum tolerable pressure of the endplates has a median value of $6.7 \mathrm{MPa}$. Our contact pressures were slightly lower than this value; however, the pressures were very near the median value and therefore, it would suggest a risk of subsidence of these implants. The OLYS cage showed a homogeneous contact pressure distributed in a large contact area. On the contrary, the NEOLIF cage exhibited concentrated contact pressures at the cage edges, as shown in other studies [52, 63]. However, 
whilst OLYS cage laid in the central part of the endplate, NEOLIF contact pressures were located in the outer part of the bony endplate, where its strength is higher [66]. It is known that subsidence risk depends on bone properties and is different for each patient $[8,67,68]$. Here, it was obtained that the contact pressures were near the maximum tolerable pressure of the bony endplates, so a deeper analysis including the local strength of the bony endplate would be necessary to discuss which cage would be more likely to subside.

Finally, the stresses' distributions in the affected and adjacent segments were analysed. The addition of PSF reduced the maximal and minimal principal stresses in the operated annulus by more than $50 \%$. The stand-alone construct also caused a reduction in the maximal stresses in the AF around 30\%; however, the minimal principal stresses were increased in some movements. Additionally, it has been hypothesised that the addition of PSF could lead to the development of IVD degeneration in the segments adjacent to the fused level due to alterations in the stress-strain distribution [69-72]. In this work, a greater increase in tension and compression stresses was reported for the finite element models with PSF, whilst the stand-alone cages slightly altered the stress distribution in the adjacent segments, which has been also seen in the literature [73]. Moreover, the influence of PSF was higher in the cranial segment than in the caudal one, because the changes on stresses were more significant in the upper segment. Changes in the biomechanical environment of biological tissues (by means of changes on the value or/ and distribution of the stresses) can cause damage to these tissues [74]. This result is in accordance with Sears el al. [75], who found that the reoperation for adjacent segment disease occurred more frequently at levels cranial rather than caudal to L4-L5 fused segments.

Although special care has been taken in computationally reproducing the physiological behaviour of the tissues and the events after the surgery, this work has several limitations. Despite spinal ligaments exhibit a non-linear, anisotropic and viscoelastic response [32, 48, 76, 77], they have been simulated as non-linear uniaxial elements. A shell or 3D model of the ligaments would allow the implementation of a more realistic material behaviour of these tissues including their preferential collagen fibre orientation. Furthermore, few experimental data are available regarding spinal ligament pretension. For deeper studies, more experimental work is needed. With respect to the exact geometry of the intervertebral cages, some simplifications were made. In the cage of OLYS implant, the top and bottom surfaces of the cage present grooves on three small zones to avoid retropulsion. These grooves were not included and a high friction coefficient was used instead, and therefore, the overall behaviour of the spine would not be affected. Regarding the PSF, a tie contact was defined at bone-screw interface. A high friction coefficient due to the threads of the screws could have been defined. However, a penalty formulation for contact definition between these elements only would affect the stress distribution in the bone around the screw, but not the movement of the screw inside the bone and, at the same time, would increase the computational time. Therefore, the assumption of a tie contact would be a valid simplification to study the intersegment movement and stresses in the intervertebral discs. Finally, only quasi-static loads were applied to the models. For a more accurate evaluation of the surgical technique, cyclic and impact loading should be considered. 
To conclude, when should stand-alone cages be considered instead of traditional PLIF surgery (cage + PSF)? Some authors [78] consider that stand-alone cages would be used in young patients with discogenic pain originating from L4-L5 and/or L5-S1 and no major degenerative changes in the posterior column due to the possible risk of adjacent segment disease associated with PSF. Moreover, Costa et al. [1] argue that when placing stand-alone cage, the facet joints are preserved and the destruction of the posterior and facet joint ligaments and of the endplates is minimal, conditions that are crucial to successful bone fusion. On the other hand, long-term follow-ups [79] have obtained that PLIF stand-alone cages were associated with good clinical outcomes but although the fusion rate was excellent, maintenance of disc heights and lordotic alignment were not achieved in the long term. Therefore, there are still pending questions. Zhang et al. [80] in a review article reported that there is no relationship between radiographic fusion and recurrence of symptoms with development of subsidence. They even suggested that subsidence may be the process of bone incorporation between cages and endplates. Moreover, these authors also relate the posterior screw fixation with an increased rate of adjacent segment degeneration. The following question could be then formulated: where is the equilibrium point between intervertebral fusion and stabilisation?

In this work, a minimally invasive posterior insertion of an intervertebral cage (OLYS and NEOLIF) was compared using a stand-alone design or adding supplementary fixation. The outcomes of these two techniques were compared, and although stand-alone cage may diminish the risk of disease progression along the spine, the spinal movement in this case might compromise the vertebral fusion.

\section{Additional file}

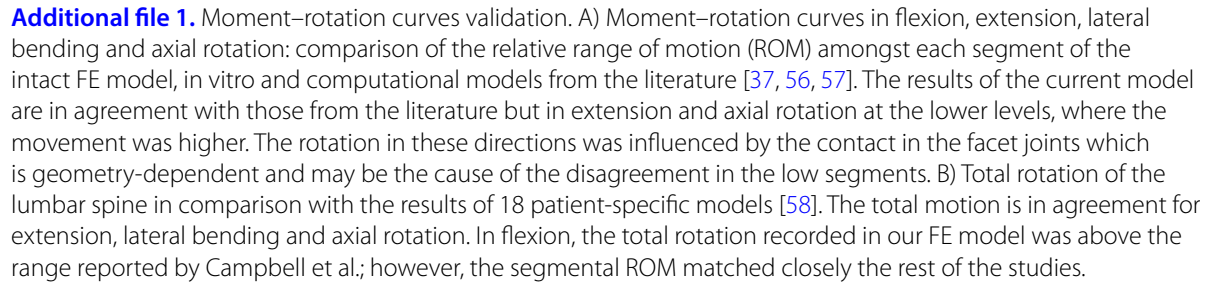

Additional file 1. Moment-rotation curves validation. A) Moment-rotation curves in flexion, extension, lateral bending and axial rotation: comparison of the relative range of motion (ROM) amongst each segment of the intact FE model, in vitro and computational models from the literature $[37,56,57]$. The results of the current model are in agreement with those from the literature but in extension and axial rotation at the lower levels, where the movement was higher. The rotation in these directions was influenced by the contact in the facet joints which is geometry-dependent and may be the cause of the disagreement in the low segments. B) Total rotation of the lumbar spine in comparison with the results of 18 patient-specific models [58]. The total motion is in agreement for extension, lateral bending and axial rotation. In flexion, the total rotation recorded in our FE model was above the range reported by Campbell et al.; however, the segmental ROM matched closely the rest of the studies.

\section{Acknowledgements}

This work was supported by the Spanish Ministry of Economy and Competitiveness under Grant DPI2016-79302-R. The funding body had no role in the design of the study and collection, analysis, and interpretation of data and in writing the manuscript.

\section{Authors' contributions}

All three authors have made substantial contributions to the following points: (1) Conception and design of the study, or acquisition of data, or analysis and interpretation of data. (2) Drafting the article or revising it critically for important intellectual content. All authors read and approved the final manuscript.

\section{Availability of data and materials}

Not applicable.

Ethics approval and acceptance to participate

Not applicable.

\section{Consent for publication}

Not applicable.

Competing interests

The authors declare that they have no competing interests. 
Received: 21 January 2019 Accepted: 14 May 2019

Published online: 22 May 2019

\section{References}

1. Costa F, Sassi M, Ortolina A, Cardia A, Assietti R, Zerbi A, et al. Stand-alone cage for posterior lumbar interbody fusion in the treatment of high-degree degenerative disc disease: design of a new device for an "old" technique. A prospective study on a series of 116 patients. Eur Spine J. 2011;20(SUPPL. 1):46-56.

2. Ahmadian A, Bach K, Bolinger B, Malham GM, Okonkwo DO, Kanter AS, et al. Stand-alone minimally invasive lateral lumbar interbody fusion: multicenter clinical outcomes. J Clin Neurosci. 2015;22:740-6.

3. Madhu TS. Posterior and anterior lumbar interbody fusion. Curr Orthop. 2008;22:406-13.

4. Zdeblick TA, Phillips FM. Interbody cage devices. Spine (Phila Pa 1976). 2003;28(15 Suppl):S2-7.

5. Sandhu HS, Turner S, Kabo JM, Kanim LEA. Distractive properties of a threaded interbody fusion device: an in vivo model. Spine (Phila Pa 1976). 1996;21:1201-10.

6. Kretzer RM, Molina C, Hu N, Umekoji H, Baaj AA, Serhan H, et al. A comparative Biomechanical analysis of stand alone versus facet screw and pedicle screw augmented lateral interbody arthrodesis: an in vitro human cadaveric model. Clin Spine Surg. 2016;29:336-43.

7. Nibu K, Panjabi MM, Oxland T, Cholewicki J. Intervertebral disc distraction with a laparoscopic anterior spinal fusion system. Eur Spine J. 1998;7:142-7.

8. Oxland T, Lund T. Biomechanics of stand-alone cages and cages in combination with posterior fixation: a literature review. Eur Spine J. 2000;9:S095-101.

9. Nemoto $O$, Asazuma T, Yato Y, Imabayashi H, Yasuoka H, Fujikawa A. Comparison of fusion rates following transforaminal lumbar interbody fusion using polyetheretherketone cages or titanium cages with transpedicular instrumentation. Eur Spine J. 2014;23:2150-5.

10. Van de Kelft E, Costa F, Van der Planken D, Schils F. A prospective multicenter registry on the accuracy of pedicle screw placement in the thoracic, lumbar and sacral level with the use of the O-arm imaging system and StealthStation navigation. Spine (Phila Pa 1976). 2012;37:1580-7.

11. Mummaneni P, Dhall SS, Eck JC, Groff MW, Ghogawala Z, Watters WC, et al. Guideline update for the performance of fusion procedures for degenerative disease of the lumbar spine. Part 11: interbody techniques for lumbar fusion. J Neurosurg Spine. 2014;21:67-74.

12. Neely WF, Fichtel F, Del Monaco DC, Block JE. Treatment of symptomatic lumbar disc degeneration with the VariLiftL interbody fusion system: retrospective review of 470 cases. Int J spine Surg. 2016;10:7.

13. Marchi L, Abdala N, Oliveira L, Amaral R, Coutinho E, Pimenta L. Radiographic and clinical evaluation of cage subsidence after stand-alone lateral interbody fusion. J Neurosurg Spine. 2013;19:110-1188.

14. Le TV, Baaj AA, Dakwar E, Burkett CJ, Murray G, Smith DA, et al. Subsidence of polyetheretherketone intervertebral cages in minimally invasive lateral retroperitoneal transpsoas lumbar interbody fusion. Spine (Phila Pa 1976). 2012;37:1268-73.

15. Allain J, Delecrin J, Beaurain J, Poignard A, Vila T, Flouzat-Lachaniette CH. Stand-alone ALIF with integrated intracorporeal anchoring plates in the treatment of degenerative lumbar disc disease: a prospective study on 65 cases. Eur Spine J. 2014:23:2136-43.

16. Gerber M, Crawford NR, Chamberlain RH, Fifield MS, LeHuec J-C, Dickman CA. Biomechanical assessment of anterior lumbar interbody fusion with an anterior lumbosacral fixation screw-plate: comparison to stand-alone anterior lumbar interbody fusion and anterior lumbar interbody fusion with pedicle screws in an unstable human cadaver. Spine (Phila Pa 1976). 2006;31:762-8.

17. Cappuccino A, Cornwall GB, Turner AWL, Fogel GR, Duong HT, Kim KD, et al. Biomechanical analysis and review of lateral lumbar fusion constructs. Spine (Phila Pa 1976). 2010;35(26 Suppl):S361-7.

18. Gonzalez-Blohm SA, Doulgeris JJ, Aghayev K, Lee WE, Volkov A, Vrionis FD. Biomechanical analysis of an interspinous fusion device as a stand-alone and as supplemental fixation to posterior expandable interbody cages in the lumbar spine. J Neurosurg Spine. 2014;20:209-19.

19. Fantigrossi A, Galbusera F, Raimondi MT, Sassi M, Fornari M. Biomechanical analysis of cages for posterior lumbar interbody fusion. Med Eng Phys. 2007;29:101-9.

20. Galbusera F, Schmidt H, Wilke H-JJ. Lumbar interbody fusion: a parametric investigation of a novel cage design with and without posterior instrumentation. Eur Spine J. 2012:21:455-62.

21. Kiapour A, Kiapour MA, Kodigudla M, Hill GM, Mishra S, Goel VK. A biomechanical finite element study of subsidence and migration tendencies in stand-alone fusion procedures - comparison of an in situ expandable device with a rigid device. J Spine. 2013;1:1-5.

22. Choi K-C, Ryu K-S, Lee SJS-H, Kim YH, Lee SJS-H, Park C-K. Biomechanical comparison of anterior lumbar interbody fusion: stand-alone interbody cage versus interbody cage with pedicle screw fixation-a finite element analysis. BMC Musculoskelet Disord. 2013;14:220.

23. Chen Y, Wang X, Lu X, Yang L, Yang H, Yuan W, et al. Comparison of titanium and polyetheretherketone (PEEK) cages in the surgical treatment of multilevel cervical spondylotic myelopathy: a prospective, randomized, control study with over 7-year follow-up. Eur Spine J. 2013;22:1539-46.

24. Liu X, Ma J, Park P, Huang X, Xie N, Ye X. Biomechanical comparison of multilevel lateral interbody fusion with and without supplementary instrumentation: a three-dimensional finite element study. BMC Musculoskelet Disord. 2017;18:63.

25. Faizan A, Kiapour A, Kiapour AM, Goel VK. Biomechanical analysis of various footprints of transforaminal lumbar interbody fusion devices. J Spinal Disord Tech. 2014;27:E118-27.

26. Jin YJ, Kim YE, Seo JH, Choi HW, Jahng TA. Effects of rod stiffness and fusion mass on the adjacent segments after floating mono-segmental fusion: a study using finite element analysis. Eur Spine J. 2013;22:1066-77. 
27. Galbusera F, Bellini CM, Anasetti F, Ciavarro C, Lovi A, Brayda-Bruno M. Rigid and flexible spinal stabilization devices: a biomechanical comparison. Med Eng Phys. 2011;33:490-6.

28. Hueng D-Y, Chung T-T, Chuang W-H, Hsu C-P, Chou K-N, Lin S-C. Biomechanical effects of cage positions and facet fixation on initial stability of the anterior lumbar interbody fusion motion segment. Spine J. 2014;39:E770-6.

29. Chen L, Yang H, Tang T. Cage migration in spondylolisthesis treated with posterior lumbar interbody fusion using BAK cages. Spine (Phila Pa 1976). 2005;30:2171-5.

30. Charles Malveaux WMS, Sharan AD. Adjacent segment disease after lumbar spinal fusion: a systematic review of the current literature. Semin Spine Surg. 2011;23:266-74.

31. Jones AC, Wilcox RK. Finite element analysis of the spine: towards a framework of verification, validation and sensitivity analysis. Med Eng Phys. 2008;30:1287-304.

32. Robertson DJ, Von Forell GA, Alsup J, Bowden AE. Thoracolumbar spinal ligaments exhibit negative and transverse pre-strain. J Mech Behav Biomed Mater. 2013;23:44-52.

33. Hortin MS, Bowden AE. Quantitative comparison of ligament formulation and pre-strain in finite element analysis of the human lumbar spine. Comput Methods Biomech Biomed Eng. 2016;19:1505-18.

34. Dardis RM, Saxena A, Shad A, Chitnavis B, Gullan R. Disc replacement technologies in the cervical and lumbar spine. In: Quiñones-Hinojosa ABT-S and SONT (ed.) Schmidek and sweet operative neurosurgical techniques, 6th edn. Philadelphia:W.B. Saunders; 2012. p. 1777-88.

35. Cegoñino J, Moramarco V, Calvo-Echenique A, Pappalettere C, Pérez Del Palomar A. A constitutive model for the annulus of human intervertebral disc (IVD): implications for developing a degeneration model and its influence on lumbar spine functioning. J Appl Math. 2014;2014:1-15.

36. Galbusera F, Schmidt H, Noailly J, Malandrino A, Lacroix D, Wilke H, et al. Comparison of four methods to simulate swelling in poroelastic finite element models of intervertebral discs. J Mech Behav Biomed Mater. 2011;4:1234-41.

37. Panjabi MM, Oxland TR, Yamamoto I, Crisco JJ. Mechanical behavior of the human lumbar and lumbosacral spine as shown by three-dimensional load-displacement curves. J Bone Jt Surg. 1994;76:413-24.

38. Buttermann GR, Beaubien BP, Freeman AL, Stoll JE, Chappuis JL. Interbody device endplate engagement effects on motion segment biomechanics. Spine J. 2009;9:564-73.

39. Moramarco V, del Pérez Palomar A, Pappalettere C, Doblaré M. An accurate validation of a computational model of a human lumbosacral segment. J Biomech. 2010;43:334-42.

40. Schmidt H, Galbusera F, Rohlmann A, Zander T, Wilke HJ. Effect of multilevel lumbar disc arthroplasty on spine kinematics and facet joint loads in flexion and extension: a finite element analysis. Eur Spine J. 2012;21 (SUPPL. 5):S663-74.

41. Ferguson SJ, Ito K, Nolte LP. Fluid flow and convective transport of solutes within the intervertebral disc. J Biomech. 2004:37:213-21

42. Argoubi M, Shirazi-Adl A. Poroelastic creep response analysis of a lumbar motion segment in compression. J Biomech. 1996;29:1331-9.

43. Lacroix D, Prendergast PJ. A mechano-regulation model for tissue differentiation during fracture healing: analysis of gap size and loading. J Biomech. 2002;35:1163-71.

44. latridis JC, Setton LA, Foster RJ, Rawlins BA, Weidenbaum M, Mow VC. Degeneration affects the anisotropic and nonlinear behaviors of human anulus fibrosus in compression. J Biomech. 1998;31:535-44.

45. Schroeder Y, Wilson W, Huyghe JM, Baaijens FP. Osmoviscoelastic finite element model of the intervertebral disc. Eur Spine J. 2006;15:361-71

46. Natarajan R, Williams J, Andersson G. Recent advances in analytical modeling of lumbar disc degeneration. Spine. 2004;29:2733-41.

47. Massey CJ, van Donkelaar CC, Vresilovic E, Zavaliangos A, Marcolongo M. Effects of aging and degeneration on the human intervertebral disc during the diurnal cycle: a finite element study. J Orthop Res. 2012;30:122-8.

48. Chazal J, Tanguy A, Bourges M, Gaurel G, Escande G, Guillot M, et al. Biomechanical properties of spinal ligaments and a histological study of the supraspinal ligament in traction. J Biomech. 1985;18:167-76.

49. Pintar FA, Yoganandan N, Myers T. Biomechanical properties of human lumbar spine ligaments. J Biomech. 1992:25:1351-6.

50. Toth JM, Wang M, Estes BT, Scifert JL, Seim HB, Turner AS. Polyetheretherketone as a biomaterial for spinal applications. Biomaterials. 2006;27:324-34.

51. Bances L. Interbody cage without instrumentation for the treatment of lumbar disc hernia. Spain: University of Zaragoza; 2016

52. Tsuang YH, Chiang YF, Hung CY, Wei HW, Huang CH, Cheng CK. Comparison of cage application modality in posterior lumbar interbody fusion with posterior instrumentation — a finite element study. Med Eng Phys. 2009;31:565-70

53. Thompson JP, Pearce RH, Schechter MT, Adams ME, Tsang IK, Bishop PB. Preliminary evaluation of a scheme for grading the gross morphology of the human intervertebral disc. Spine (Phila Pa 1976). 1990;15:411-5.

54. Du L, Sun X, Zhou T, Li Y, Chen C, Zhao C, et al. The role of cage height on the flexibility and load sharing of lumbar spine after lumbar interbody fusion with unilateral and bilateral instrumentation : a biomechanical study. BMC Musculoskelet Disord. 2017;18:474-81.

55. Wood RA, Favor RJ. Titanium alloys handbook. Wright-Patterson, Ohio: Center, Airforce Materials Laboratory. Metals, Ceramics Information; 1972.

56. Guan Y, Yoganandan N, Moore J, Pintar FA, Zhang J, Maiman DJ, et al. Moment-rotation responses of the human lumbosacral spinal column. J Biomech. 2007:40:1975-80.

57. Park WM, Kim K, Kim YH. Effects of degenerated intervertebral discs on intersegmental rotations, intradiscal pressures, and facet joint forces of the whole lumbar spine. Comput Biol Med. 2013;43:1234-40.

58. Campbell JQ, Coombs DJ, Rao M, Rullkoetter PJ, Petrella AJ. Automated finite element meshing of the lumbar spine: verification and validation with 18 specimen-specific models. J Biomech. 2016;49:2669-76.

59. Patel RR, Noschchenko A, Carpenter RD, Baldini T, Frick CP. Evaluation and prediction of human lumbar vertebrae endplate mechanical properties using indentation and computed tomography. J Biomech Eng. 2018;2019(140):1-9. 
60. O'Sullivan PB. Lumbar segmental "instability": clinical presentation and specific stabilizing exercise management Man Ther. 2000;5:2-12.

61. Marchi L, Abdala N, Oliveira L, Amaral R, Coutinho E, Pimenta L. Stand-alone lateral interbody fusion for the treatment of low-grade degenerative spondylolisthesis. Sci World J. 2012;2012:1-7.

62. Techy F, Mageswaran P, Colbrunn RW, Bonner TF, McLain RF. Properties of an interspinous fixation device (ISD) in lumbar fusion constructs: a biomechanical study. Spine J. 2013;13:572-9.

63. Chen SH, Chiang M-C, Lin J-F, Lin S-C, Hung C-H. Biomechanical comparison of three stand-alone lumbar cages-a three-dimensional finite element analysis. BMC Musculoskelet Disord. 2013;14:1-13.

64. Lee $K$, Teo E. Material sensitivity study on lumbar motion segment ( $L 2-L 3)$ under sagittal plane loadings using probabilistic method. J Spinal Disord Tech. 2005;18:163-70.

65. Sohn M-J, Kayanja MM, Kilinçer C, Ferrara LA, Benzel EC. Biomechanical evaluation of the ventral and lateral surface shear strain distributions in central compared with dorsolateral placement of cages for lumbar interbody fusion. J Neurosurg Spine. 2006;4:219-24

66. Lowe TG, Hashim S, Wilson LA, O'Brien MF, Smith DAB, Diekmann MJ, et al. A biomechanical study of regional endplate strength and cage morphology as it relates to structural interbody support. Spine (Phila Pa 1976). 2004;29:2389-94.

67. Grant JP, Oxland TR, Dvorak MF, Fisher CG. The effects of bone density and disc degeneration on the structural property distributions in the lower lumbar vertebral endplates. J Orthop Res. 2002;20:1115-20.

68. Kelly N, Harrison NM, McDonnell P, McGarry JP. An experimental and computational investigation of the post-yield behaviour of trabecular bone during vertebral device subsidence. Biomech Model Mechanobiol. 2013;12:685-703.

69. Etebar S, Cahill DW. Risk factors for adjacent-segment failure following lumbar fixation with rigid instrumentation for degenerative instability. J Neurosurg. 1999:90(2):163-9.

70. Glaser J, Stanley M, Sayre H, Woody J, Found E, Spratt K. A 10-year follow-up evaluation of lumbar spine fusion with pedicle screw fixation. Spine Spine (Phila Pa 1976). 2003;28:1390-5.

71. Cegoñino J, Calvo-Echenique A, Pérez-del Palomar A. Influence of different fusion techniques in lumbar spine over the adjacent segments: a 3D finite element study. J Orthop Res. 2015;33:993-1000.

72. Urban JPG, Roberts S. Degeneration of the intervertebral disc. Arthritis Res Ther. 2003;5:120-30.

73. Chen S-H, Tai C-L, Lin C-Y, Hsieh P-H, Chen W-P. Biomechanical comparison of a new stand-alone anterior lumbar interbody fusion cage with established fixation techniques - a three-dimensional finite element analysis. BMC Musculoskelet Disord. 2008;9:88

74. Carver W, Goldsmith EC. Regulation of tissue fibrosis by the biomechanical environment. Biomed Res Int. 2013;2013:10

75. Sears WR, Sergides IG, Kazemi N, Smith M, White GJ, Osburg B. Incidence and prevalence of surgery at segments adjacent to a previous posterior lumbar arthrodesis. Spine J. 2011;11:11-20.

76. Bradshaw R, Russell A, Bowden AE. Spinal ligaments: anisotropic characterization using very small samples. Exp Appl Mech. 2011;6:429-36.

77. Hortin M, Graham S, Boatwright K, Hyoung P, Bowden A. Transversely isotropic material characterization of the human anterior longitudinal ligament. J Mech Behav Biomed Mater. 2015;45:75-82.

78. Udby PM, Bech-azeddine R. Clinical outcome of stand-alone ALIF compared to posterior instrumentation for degenerative disc disease: a pilot study and a literature review. Clin Neurol Neurosurg. 2015;133:64-9.

79. Baeesa SS, Medrano BG, Noriega DC. Long-term outcomes of posterior lumbar interbody fusion using stand-alone ray threaded cage for. Asian Spine J. 2016;10:1100-5.

80. Zhang J, Poffyn B, Sys G, Uyttendaele D. Are stand-alone cages sufficient for anterior lumbar interbody fusion? Orthop Surg. 2012:4:11-4.

\section{Publisher's Note}

Springer Nature remains neutral with regard to jurisdictional claims in published maps and institutional affiliations. 